\title{
Guillain Barre Syndrome: Major Cause of Acute Flaccid Paralysis in Children and Adolescents of Nepal
}

\author{
Sharma KS ${ }^{1}$, Singh $\mathbf{R}^{2}$, Shah $\mathbf{G S}^{3}$
}

${ }^{1}$ Dr. Krishna Sagar Sharma, MBBS. MD. Registrar, Paediatric and Adolescent Oncology Unit Chief, B.P. Koirala Memorial Cancer Hospital, Bharatpur, Chitwan, ${ }^{2}$ Prof Rupa Singh, MBBS.MD. Professor, Department of Paediatrics and Adolescent Medicine, B.P. Koirala Institute of Health Sciences, Dharan, Sunsari, Nepal, ${ }^{3}$ Dr. Gauri Shankar Shah, MBBS. MD. Associate Professor, Department of Paediatrics and Adolescent Medicine, B.P. Koirala Institute of Health Sciences, Dharan, Sunsari, Nepal.

Address for correspondence: Dr. Krishna Sagar Sharma, E-mail: krisa_72003@yahoo.com

\begin{abstract}
Introduction. Guillain Barre Syndrome (GBS) is a post infectious polyneuropathy involving mainly motor but sometimes sensory and autonomic nerves. It is an acquired disease of the peripheral nerves that is characterized by rapidly progressing paralysis, areflexia and albumino-cytological dissociation in CSF. Methodology: Prospective, descriptive, observational, hospital based study was carried out to find out the clinico-epidemiological features of GBS including existing treatment modalities and its outcome. All cases fulfilled the criteria for AFP (Acute flaccid Paralysis) surveillance was included. Cases were reviewed for full medical history and examinations. To confirm the diagnosis, necessary investigations were carried out and combined with clinical symptoms. Results: Thirty patients were included in the study during study period. Among them $90 \%$ were diagnosed as GBS, $7.4 \%$ patients of GBS were associated with hypokalemic paralysis, $7.4 \%$ diagnosed as transverse myelitis and $3.7 \%$ diagnosed as idiopathic neuropathy. Different types of GBS were classified as AIDP (Acute inflammatory demyelinating polyneuropathy) $62.96 \%$, AMAN (Acute motor axonal neuropathy) - 25.52\%, AMASAN (Acute motor and sensory axonal neuropathy) - 3.3\% and MFS (Miller fisher's syndrome) - 6.6\% according to NCV result. Male female ratio is $1.7: 1.0$. There was $14.8 \%$ patients had relapse within 5 year. Associated diseases were URTI, pneumonia, sore throat and diarrhea. Facial Nerve palsy was commonest cranial nerve involvement.Sixty percentage of patients presented with sensory symptoms. There was transient bowel and bladder involvement in $20 \%$ of the cases. $69.2 \%$ patients became bed ridden at the nadir. There was albumin-cytological dissociation in $80 \%$ case. Majority of patients improved with supportive treatment alone, $19.5 \%$ patient required ventilator support among them $40 \%$ died. $7.4 \%$ of cases expired during treatment. Half of the patients fully recovered within 3 months. Conclusion: GBS is the commonest cause of AFP, AIDP being commonest subtype in our setting. We have to improve our existing treatment facilities and extend to different centers to detect and treat GBS. Most of the patients improve with supportive treatment alone. Ventilator support indicates grave prognosis.
\end{abstract}

Key words: GBS (Gullein Barre Syndrome), AFP (Acute flaccid Paralysis), AIDP (Acute inflammatory demyelinating polyneuropathy, AMAN (Acute motor axonal neuropathy), AMASAN (Acute motor and sensory axonal neuropathy), MFS (Miller fisher's syndrome).

\section{Introduction}

G uillain Barre Syndrome (GBS) is a post infectious polyneuropathy involving mainly motor but sometimes also sensory and autonomic nerves ${ }^{1}$.GBS is an acquired disease of the peripheral nerves that is characterized clinically by rapidly progressing paralysis, areflexia and albumino-cytological dissociation ${ }^{2}$. Earliest description of this disease is probably that of Word Rob and Oliver in 1834, but the syndrome as first described in 1859 by Jean Baptiste Octave Landry, who identified 
the clinical features of the disease and termed it as 'Acute ascending paralysis. Osler reported the same disease in 1982 as febrile polyneuritis ${ }^{3}$. In 1916, Guillan, Barre and Strohl published their observation of the albumin cytological dissociation on cerebrospinal fluid examination of two shoulders who had presented with paralysis and areflexia ${ }^{2}$. A comprehensive pathological account of GBS was that of Haymaker \& Kernohan (1949) who stressed that edema of the peripheral nerves was the important changes in the early stage of disease $^{3}$. Asbury, Arnoson and Adam (1969) established the essential lesion; it is a perivascular mononuclear inflammatory infiltrate of the root and nerves ${ }^{3}$. In 1980 s $^{2}$ and 1990s saw the development of plasma exchanges, intravenous immunoglobulin and all of which reduced the mortality and morbidity ${ }^{2}$. The watershed development in the last decade, however, has been the characterization of variants of GBS and recognition of pathological association of campylobacter jejuni infection with the motor axonal form of $\mathrm{GBS}^{3}$.

GBS occurs in all age groups and has an annual incidence varying from 0.4 to 1.7 cases per 100000 population. The reported incidence for children under 15 years is similar to adults ${ }^{2}$. It occurs in all part of the world in all seasons, affects both children and adult of both sex ${ }^{2}$. In post polio era, it is the most common cause of an acute generalized paralysis ${ }^{2}$. Though GBS is nonseasonal and non-epidemic, the existence of an axonal variant of GBS has been confirmed by observations on an annual seasonal epidemic that occurs in northern China in summer ${ }^{4}$. There is a slightly male predominance with male to female ratio of 1.5:1. while most of the cases occurs sporadically; occurrence of epidemic clusters of GBS has been described ${ }^{2}$. According to the Acute flaccid Paralysis (AFP) surveillance record of Nepal there are 192, 214 and 224 cases of AFP in 2060 (2003-2004), 2061(2004-2005) \& 2062 (2005-2006) respectively ${ }^{5}$. World Health Organization (WHO) has established standards to check the efficacy of surveillance systems in each country, polio-endemic or not, should be able to detect at least one case of AFP not caused by polio every 100,000 children under age 15 . If a country can detect AFP causes corresponding to this rate, one can be reasonably certain that all polio cases among these paralyzed children have been identified ${ }^{6}$. Only one cases of polio was recorded in 2006, other cases of AFP neither were nor categorized properly. As post polio era GBS is the commonest causes of AFP in developed countries. Most of the cases in our setting are also assumed to be GBS.

\section{Materials and Methods}

Prospective, descriptive, observational, hospital based study was carried out at to find out the clinicoepidemiological features of GBS in eastern part of Nepal including clinical presentations, risk factors, existing treatment modalities, prognosis of the disease in relation to its severity and outcome in the tertiary care centre. All cases fulfilling the criteria for AFP surveillance were included in study. Children enrolled in study were seen in emergency, outpatient department (OPD), Pediatric wards and pediatric intensive care unit (PICU). Cases were reviewed for full medical history, general physical and detail systemic examination, in order to confirm the diagnosis, necessary investigations were made. All children up to 15 years, coming under AFP surveillance were included. Features required for Diagnosis includes progressive weakness of both legs and arms and areflexia ${ }^{7}$. Clinical features supportive of diagnosis includes progression over days to a couple of weeks, relative symmetry of signs, mild sensory symptoms or signs, cranial nerves involvement (bifacial palsies) Recovery beginning 2-4 wks after progression ceases, autonomic dysfunction, and absence of fever at onset ${ }^{7}$. Laboratory features supportive of diagnosis includes elevated CSF protein with < 10 cells/micro liter and electro diagnostic features of nerve conduction slowing or block?

\section{Statistical Analysis}

The data collected were compiled and entered in MS Excel. Statistical analysis was carried by using SPSS pc+ 11.0 versions to find out different type of correlation and statistical values. $P$ value $<0.05$ was taken as a statistically significance.

\section{Results}

Thirty patients were included in the study during 16 months of study period. Among them 27 (90\%) were diagnosed as GBS, $2(7.4 \%)$ patients of GBS were associated with hypokalemic paralysis, 2 patients $(7.4 \%)$ diagnosed as transverse myelitis and 1 patient $(3.7 \%)$ diagnosed as idiopathic neuropathy.

All of 27 GBS patients had undergone NCV test and classified as AIDP (Acute inflammatory demyelinating polyneuropathy)-17 patients (62.96\%), AMAN (Acute motor axonal neuropathy) - 7 patients (25.52\%), AMASAN (Acute motor and sensory axonal neuropathy) -1 patient (3.3\%) and MFS (Miller fisher's syndrome) - 2 patients $(6.6 \%)$ according to NCV result.

GBS is commonest cause of AFP, AIDP being commonest subtype in our setting. There was associated preceding illness in GBS. Majority patients presented with symmetrically ascending paralysis with gradual onset involving all limbs. Male were more affected in 
present study with male female ratio as 1.7:1.0. There was no significant age distribution but slightly higher patient from pre adolescent to young adults were found. There was no seasonal variation, no significant status with immunization, but $14.8 \%$ patients had relapse within 5 year. Associated diseases were URTI, pneumonia, sore throat, diarrhea in majority of patients.

Facial Nerve palsy was commonest cranial nerve (CN) involvement, $60 \%$ of patients presented with sensory symptoms like pain, tingling and numbness. There was transient bowel and bladder involvement in $20 \%$ of the cases. All patients became areflexic during the course of illness with $69.2 \%$ becoming bed ridden at the nadir. $77.8 \%$ patients had elevated CSF protein and $88.2 \%$ patients had less than 10 CSF lymphocytes after 2 week of illness.

\section{Nerve Conduction Velocity Study}

\begin{tabular}{|l|c|c|}
\hline NCV & Frequency $(\mathbf{n}=\mathbf{2 7})$ & Percent $\mathbf{( \% )}$ \\
\hline AIDP & 17 & 63.0 \\
\hline AMAN & 7 & 25.9 \\
\hline AMASAN & 1 & 3.7 \\
\hline MFS & 2 & 7.4 \\
\hline
\end{tabular}

$63 \%$ patients had acute inflammatory demylinating polyradiculopathy. 23 patients required only supporting treatment including steroids and physiotherapy but five patients required ventilator support. Two patients were expired during treatment (On Ventilator due to respiratory failure). $63 \%$ of patient discharged within 1 week of admission. Hospital mortality was $7.4 \%$ and $85.18 \%$ were discharged after improvement. Out of two one patient expired after 32 days due to secondary infection with aspiration, next patient expired immediately after admission on day 1 due to autonomic instability. Hughes scale was used for monitoring of weakness, $43.47 \%$ patients became healthy at 3 month of illness; other patients were improving only $8.69 \%$ patients remain bed ridden without further deteriorations.

There was no significant correlation found between different modes of clinical presentation like duration of weakness, type of weakness. Involvement of cranial nerve was analyzed with SPSS pc+ 11.0 version and no significant correlation found. There was albumincytological dissociation in $80 \%$ case. Majority of patients improved with supportive treatment alone, $19.5 \%$ patient required ventilator support among them $40 \%$ died. Majority of patient discharged within 1 week of admission with some improvement. $7.4 \%$ of cases expired during treatment, at 3 month follow-up almost half patients recovered fully and remaining patients improved on follow up.

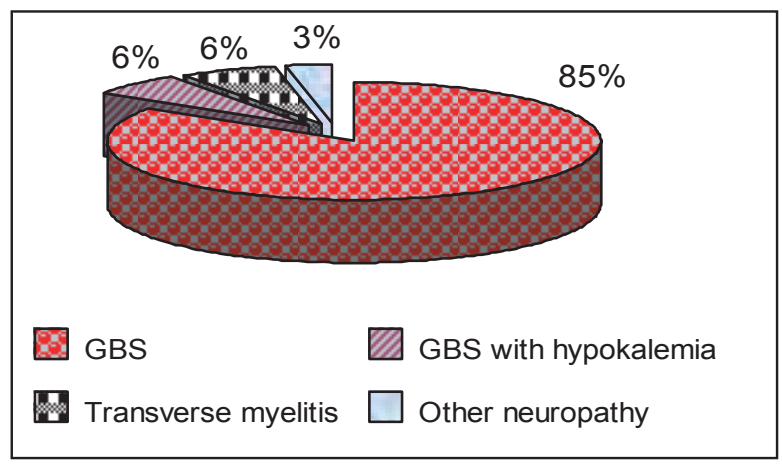

Fig 1: Different types of AFP

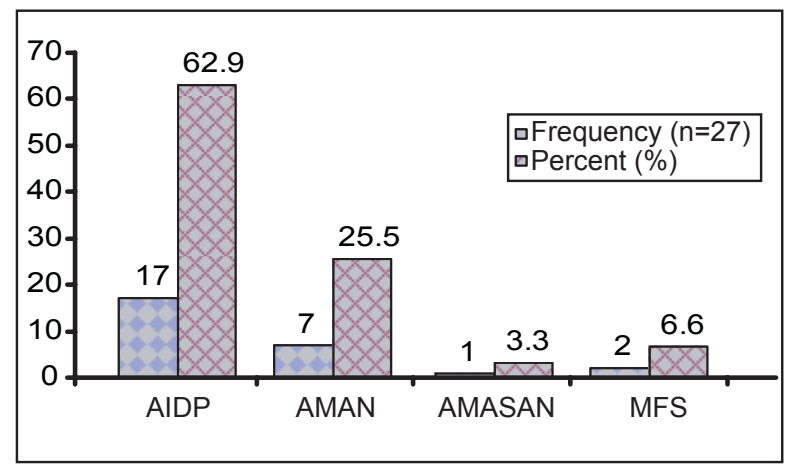

Fig 2: Types of GBS

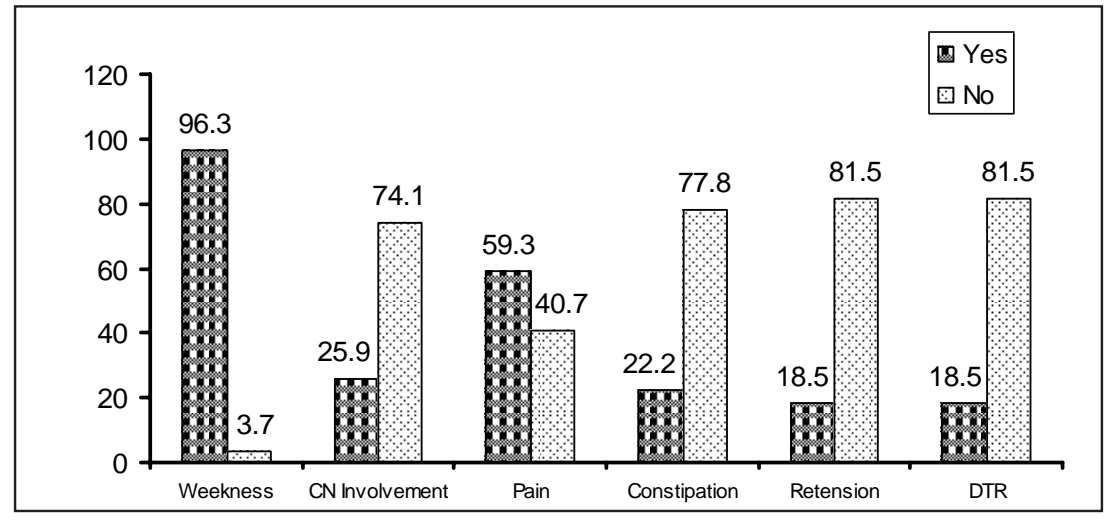

Fig 3: Clinical Presentation 


\section{Discussion}

GBS is commonest cause of AFP, AIDP being commonest subtype in our setting. There was associated preceding illness in GBS. Majority patients presented with symmetrically ascending paralysis with gradual onset involving all limbs. Male were more affected in present study with male female ratio as 1.7:1.0. There was no significant age distribution but slightly higher patient from pre adolescent to young adults were found. There was no seasonal variation, no significant status with immunization, but $14.8 \%$ patients had relapse within 5 year. Patient had associated illness like URTI, pneumonia, sore throat, diarrhea in majority patients. Facial Nerve palsy was commonest cranial nerve involvement, in $60 \%$ of patients presented with sensory symptoms like pain, tingling and numbness. There was transient Bowel and bladder involvement in $1 / 5^{\text {th }}$ of the cases. All patient became areflexia during the course of illness with $69.2 \%$ became bed ridden at nadir. There was albumino-cytological dissociation in $80 \%$ case. Majority patient improved with supportive treatment alone, $19.5 \%$ patient required ventilator support among them $40 \%$ mortality occurred. Majority of patient discharged within 1 week of admission with some improvement. $7.4 \%$ cases are expired during treatment, at 3 month follow-up almost half patient become healthy and remaining patient were improving on follow up. GBS is the commonest cause of the acute flaccid paralysis. It has been observed in Nepal from long time, which was recorded nationwide through AFP surveillance. Our present study was carried out to find out the clinico-epidemiological features of GBS in eastern part of Nepal (carried out at BPKIHS), the only tertiary care centre in Eastern Nepal.

Population based surveillance in Netherlands $(1992-94)^{8}$ shows the incidence of GBS as $30.8 \%$ Idiopathic Neuropathy with AFP $12 \%$ and infection related AFP $40 \%$. AIDP was commonest of all types of GBS. In western countries, AIDP was highest; where as in Northern China AMAN was the highest incidence. Rees $\mathrm{JH}$, et al (1995), England study ${ }^{9}$ shows $85 \%$ AIDP and MFS $5 \%{ }^{10}$. Ho TW, et al in Western China study ${ }^{11}$ show AIDP - 19\%, AMAN 65\%, AMASAN 10-15\%. Udaya Senevaratne, Srilanka Study $(2000)^{12}$ shows, $76 \%$ AIDP, $24 \%$ AMAN and 10\% comprises other subtype of GBS which was comparable to our study. Rong KL, et al (1997) ${ }^{13}$ Taiwan study showed AIDP (49\%), AMAN (4\%), MFS (18\%) and others $29 \%$. Emilia Romagna, Italy study (1992-93) ${ }^{14}$ showed AIDP (36\%), AMAN (14\%) and MFS (13\%). As shown in most of the population based studies our study had shown highest number of AIDP patients.

Rees $\mathrm{JH}$, et al (1998) in south east England study ${ }^{15}$ had shown slightly predominant in adolescents and young adults. Beghi E, et al (1985) Netherlands study ${ }^{16}$, Larsen JP, et al (1985) Norway study, Vankoninsveld R, Netherlands study $(2000)^{17}$ show there was linear increase in incidence with age. In this study though there was no specific age variation, most patients were between $11-15$ years (40\%) of age.Netherlands ${ }^{8}$ study shows no consistent seasonal variation. But EmiliaRomagna study group Italy (1992-93) ${ }^{14}$, Beghi E, et al (1985) study, rural northern China study show relatively higher incidence in summer months, which was associated with increased infection with campylobacter infection. Dana I et al study shows $2 / 3^{\text {rd }}$ children had associated illness like fever (59\%) and diarrhea (26\%). In Emilia Romagna study in Italy (1999) ${ }^{14}$ 65\% cases had associated infection (59\% fever, $18.2 \%$ diarrhea); Cheng Q, et al Sweden study (2000) ${ }^{18}$ shows $60 \%$ respiratory tract illness, 28\% diarrhea, 45\% RTI. Paul $\mathrm{H}$, et al $(2001)^{19}$ study show $71 \%$ associated illness, Udaya Seneviratne, Srilanka study $(2000)^{12}$ show $60 \%$ associated illness (20\% Diarrhea, 40\% Respiratory tract infection), Nicholas DL, et $\mathrm{al}^{20}$ study shows $71 \%$ associated illness, Taiwan study (1997) show 67\% associated illness (54\% respiratory infection). Jacob BC,et al Netherlands study (1998) ${ }^{21}$ show $32 \%$ diarrhea and $19 \%$ respiratory tract illness. In this study, $73.5 \%$ patients presented with associated illness. $66.7 \%$ patient with preceding history of fever within 1 week, $22.2 \%$ patients with diarrhea, and $41.8 \%$ respiratory illness.

Udaya Senevirante (2000)12 shows 53\% CN weakness, Emilia Romagna Italy study (1992-93) 53\% Spain study (1994) by Sedano MJ, et al shows $50 \%$ of Cranial Nerve weakness. In this study $25.5 \%$ patient shows Cranial Nerve weakness, facial nerve weakness being the commonest. In present studies lesser number of cranial nerve involvements was found as compared to others. Mortality rate ranges from $2-13 \%$ in different studies. Dana I, et $a^{22}$ study shows $5 \%$, Italian GBS study group shows (up to $12 \%$ ), Cherg Q, et al (2000) $)^{18}$ shows $8 \%$, Nicholas, et al $(1998)^{20}$ shows $4 \%$, Italian study (1988-93) 9\%, South England (1993-94) shows $9 \%$,Voston MGH (1962-81) shows $2 \%$, Brazil study (2003) shows $10 \%$ mortality among all GBS case. In our study mortality rate was $7 \%$ which is comparable to other studies. In our study majority of patients recovered over 1 year period. At 3 months follow-up shows $43.47 \%$ became healthy and $9 \%$ bedridden. Italian GBS study group shows $15 \%$ bed ridden, where as Chang $Q$, et al (2000) study shows $4 \%$ bed ridden at 3 month follow-up.

\section{Conclusion}

GBS is the commonest cause of AFP, AIDP being commonest subtype in our setting. We have to improve our existing treatment facilities and extend to different centers to detect and treat GBS. Most of the patients 
improve with supportive treatment alone. Ventilator support indicates grave prognosis. Adequate supportive treatment and long term follow up is needed to insure recovery from illness. Over all cures is good except respiratory failure.

\section{Acknowledgements}

Authors would like to acknowledge the patients and their parents who took part in the study and other persons who involved directly and indirectly.

\section{Conflict of Interest}

This article is based on the final thesis (part of compulsary thesis submission) report submitted to Department of Paediatrics and Adolescent Medicine, BP Koirala Institute of Health Sciences, Dharan.

Funding: None.

Permission from IRB: Yes.

\section{References}

1. Gullian Barre Syndrome. In: Kliegman RM, Behrman RE, Jenson HB, Stanton BF. Nelson Textbook of Pediatrics. 18th Edition Philadelphia; Elsevier; 2008. Sarnat HB. p.2565-566.

2. Vedanarayanan V, Chaudhary V. Guillain Barre Syndrome Recent advance. Indian $J$ Pediatr 2000;67(9):635-49.

3. Victor M, Popper AH. Adams and Victor's Principle of Neurology. $7^{\text {th }}$ Edition. Mc-Hill co. inc., 2001.

4. Devid IG, Peter LL. Greenfield's Neuropathology. $6^{\text {th }}$ Edition London; Arnold; 1997.

5. Surveillance of AFP for polio eradication field guide, WHO/HMG Nepal.

6. Towards eradicating polio in South-East Asia 19972000. WHO.

7. Water GB, Robert BD, Gerald M, Josesh J. Neurology in clinical practice 4th Edition. Philadelphia; Elsevier Inc; 2004.

8. Oostvogel PM. Surveillance of AFP in the Netherlands (1992-1994). WHO 1998, 76(1); 55-62.

9. Rees $\mathrm{JH}$, Thompson RD, Smeeton NC, Hughes RA. An epidemiological study of Guillain Barre Syndrome in south east England. J Neurol Neurosurg Psychiatry 1998; 64(1):74-77.
10. Vittorio G, Enrico G. Epidemiology of the GBS. Curr Opin Neurol 2001;14(5):605-613.

11. Ho TW, Li CY, Cornblath DR, Gao CY, Asbury AK, Griffin JW, McKhann GM.. Patterns of recovery in the GBS. Neurology 1997;48(3):695-700.

12. Seneviratne U. Guillain Barre Syndrome. Postgrad Med J 2000;76:774-782.

13. Lyu RK, Tang LM, Cheng SY, Hsu WC, Cheng ST. Guillain-Barre Syndrome in Taiwan: a clinical study of 167 patients. J Neurol Neurosurgery Psychiatry 1997; 63(4): 494-500.

14. Green D. Infectious polyneuritis and Professor Andre Strohl: A historical note. N Engl J Med 1962; 265:821-22.

15. Rees JH, Thompson RD, Smeeton NC, Hughes RA. An epidemiological study of Guillain Barre Syndrome in south east England. I Neurol Neurosurg Psychiatry 1998; 64(1):74-77.

16. Emilia-Romagna study group on clinical and epidemiological problems in Neurology. A prospective study on the incidence and prognosis of Guillain Barre Syndrome in Emilia-Romagna region, Italy (1992-1993). Neurology 1997; 48(1):214-221.

17. Van Koningsveld R, Van Doorn PA, Schmitz PI, Ang CW, Van der Meché FG Mild form of Guillain Barre Syndrome in an epidemiologic survey in the Netherlands. Neurology 2000;54(3):620-25.

18. Cheng Q, Jiang GX, Press R, Andersson M, Ekstedt $B$, Vrethem et.al. Clinical epidemiology of GBS in adults in Sweden 1996-1997: A prospective study. Eur J Neurol 2000; 7(6):685-692.

19. Paul HG, Asa JW. Early Electro diagnostic Findings in GBS. Arch Neurol 2001;58:913-17.

20. Lawn ND, Wijdicks EF. Fatal Guillain Barre Syndrome. Neurology 1999; 52:635-38.

21. Jacobs $B C$, Rothbarth $P H$, van der Meché FG, Herbrink P, Schmitz PI, de Klerk MA, van Doorn PA. The spectrum of antecedent infections in GBS: A case-control study. Neurology 1998;51(4):1110-115.

22. Newswanger DL, Warren CR.Gullian- Barre Syndrome. Am Fam Physician. 2004;69(10):2405410.

\section{How to cite this article?}

Sharma KS, Singh R, Shah GS. Guillain Barre Syndrome; Major Cause of Acute Flaccid Paralysis in Children and Adolescents of Nepal. J Nep Paedtr Soc 2011;31(2):93-97. 